Rakenteiden Mekaniikka (Journal of Structural Mechanics)

Vol. 53, No. 3, 2020, pp. 259-280

https://rakenteidenmekaniikka.journal.fi/index

https://doi.org/10.23998/rm.77612

(c) 2020 The Authors

Open access under license CC BY 4.0

\title{
Overview of laser-welded thin-walled joints fatigue per- formance and a statistical method for defect analysis
}

\author{
Rami Kokko ${ }^{1}$, Joona Vaara, Teemu Kuivaniemi and Tero Frondelius
}

Summary Welding always has a deteriorating effect on fatigue strength in structures under dynamic loading. Weld joints induce discontinuity in structure geometry and the microstructure. Welding induced discontinuity, and defects allow for potential fatigue cracks that lead to the failure of welded parts or structures. The laser welding process differs from conventional arc welding in process and joint type. The most significant advantage in laser welding comes from the deep penetrating mode of welding, which also brings challenges to the soundness of the weld. The benefits of laser welding are most evident in the manufacture of sheet metal products such as sandwich panels. In literature, laser welding is generally dealt with by using different parts of the overall process without taking the fatigue point of view into account. In this article, the process of laser welding is discussed, while keeping fatigue strength in perspective. The fatigue data of laser welded joints is studied in order to find defect distribution that explains fatigue strength distribution in tests. The suitability of traditional fatigue assessment for laser welding is also discussed.

Key words: welding, laser welding, literature review, fatigue

Received: 8 January 2019. Accepted: 12 December 2020. Published online: 4 September 2020.

\section{Introduction}

The demand for laser welding is rising in the industry, and thus, research concerning optimisation, simulation and the fatigue behaviour of laser welding has been an object of interest. The main benefits of laser welding can be exploited in joints, such as the lap joint, where laser welding can be used as "continuous spot welding", as this welding process is easy to control [1,2]. The lap joint can be made by welding through from one side, making a complete seam with one pass, which provides many opportunities for the design of lightweight structures [3-5]. Lightweight structures, like sandwich panes made from sheet metal, have very good weight to stiffness ratio, even when made from thin sheets.

The welding always leads to defects that have a deteriorating effect on fatigue strength $[1,6,7]$. The fatigue strength results have dispersion caused by varied number and size of defects. The process of laser welding needs to be understood because the defects are

\footnotetext{
${ }^{1}$ Corresponding author: rami.kokko@gbw.fi
} 
forming in the process of welding. With a better understanding of defects on the welded joint, the fatigue strength assessment can be made more precise.

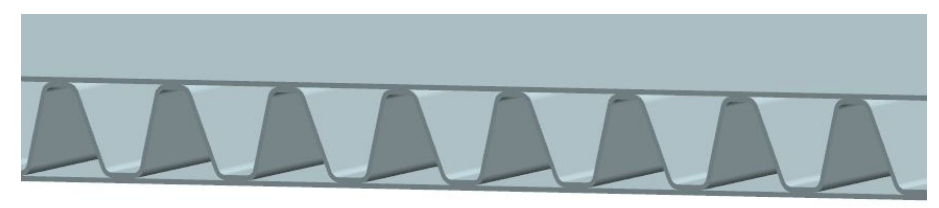

Figure 1. The principle of sandwich plate structure.

\section{Characteristics of laser welding}

Small and focused energy input, which is characteristic for laser welding, leads to beneficial features compared with traditional arc welding. The high-power density leads to low heat input, as welding is focused on a very small area, only where welding is needed. This lead to a narrow heat-affected zone, lower distortions and residual stresses and a beneficial microstructure [1,9-11]. The heat input is the relation between welding power and speed, and it can be written in the form of $\mathrm{J} / \mathrm{mm}$. The speed of laser welding is significantly higher compared to traditional welding process $[1,12,13]$. The high energy density leads to a deep penetrating welding mode, which allows for an increase of the speed without compromising the quality of welding.

The laser welding process is easily automated [1,2], and it is generally done with an automated process. The automation raises challenges in the process, as it needs to be preconfigured and programmed. Also, in order to produce the best possible quality weld, parameters need to be right. The quality of the weld can drop significantly when the parameters are poorly set $[14,15]$.

A laser-welded joint is more visually sound and unnoticeable compared to a traditional weld joint. In Figure 2, an example of the difference between a submerged arc welded, SAW, and laser welded joint is given. The weld bead of laser welding is minimised because no additional material is generally added in laser welding.
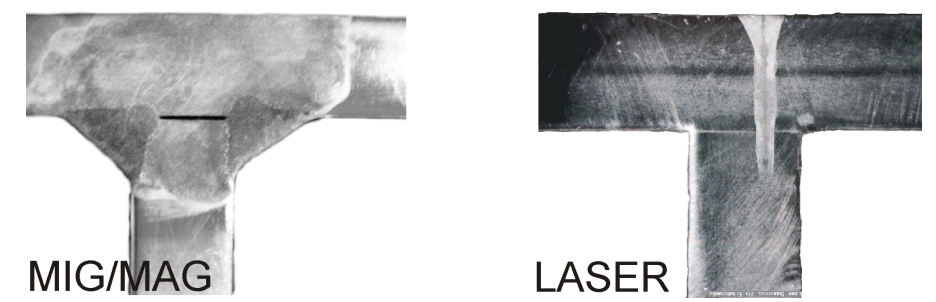

Figure 2. Difference in weld form of T-joint in MIG/MAG and laser welding. Figures from HT-laser Oy [16]

\section{Physics of laser welding}

The laser is applicable to welding, if a sufficient power density and wavelength is reached $[9,17]$. The laser welding can be generally done in two different modes: deep penetrating and heat conduction welding. Deep penetrating welding or keyhole welding is a more common mode for laser welding. The term comes from the shape of the weld, where the 
laser beam penetrates into a material, forming a narrow molten pool. The principle of deep penetrating welding is shown in Figure 3. The heat conduction is similar to conventional arc welding methods, where the heat is transferred into the material by conduction.

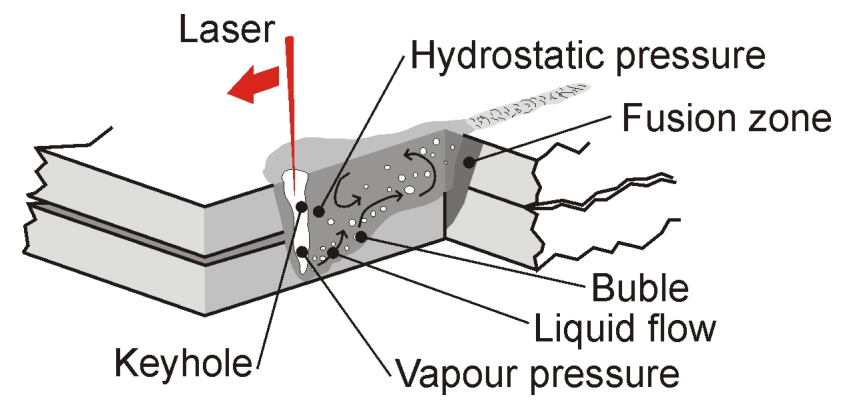

Figure 3. Principle of deep penetrating welding

\section{Forming of keyhole}

In laser welding, heat is inducted into the part with a laser beam [9]. The keyhole cavity starts to form when the laser beam's energy is absorbed in the contact area, and the weldable material starts to melt. When a sufficient amount of heat is conducted to the metallic material, atomic bonds break, further generating plasma of vaporised metal atoms and surrounding gases, when electrons are removed [18]. The energy density needs to be around $1 \mathrm{MW} / \mathrm{cm}^{2}$ for deep penetrating welding $[9,10]$.

The penetrating cavity, keyhole, is formed by the depression of the liquid surface, as the laser "drills" trough material [9, 10, 19]. Welding forms a molten pool, which when solidified, forms a welding joint. The keyhole is held open by the recoil pressure of evaporation particles in the keyhole, where the molten pool hydrostatic pressure tends to close the keyhole [18]. Laser welding involves multiple physical phenomena, starting from absorption of the surface, metal melting, keyhole formation, keyhole plasma formation, laser plasma interaction, liquid pressure, plasma interaction, metal solidification etc., which effect the quality of weld and thus fatigue properties [20].

\section{Succeed and efficiency of laser welding}

The usage of protection gas makes the process more stable, but keyhole welding can be done without it. The energy of the laser is absorbed mainly within two mechanisms of an evaporation region: inverse Bremsstrahlung and Fresnell absorption [9]]. In the inverse Bremsstrahlung, the energy absorption takes place in formed plasma, where it radiates to the weldable part. The usage of protective gas makes the keyhole more stable by forming a more stable plasma in the laser-gas interaction [10]. However, the plume (vaporised material) and plasma have a defocusing effect on the laser beam and, thus, can reduce the efficiency of the process and even change the mode to conduction welding [19]. In the Fresnell absorption, multiple reflections at the walls of the keyhole transfer the energy of the beam. Absorption is dependent on the polarisation of the beam and its efficiency, as from material reflectivity, which may even lead to the keyhole not forming [19,21]. The energy losses in welding are approximately $30 \%$ due to the imperfections and reflection of the weldable part [22]. 
The stability of the keyhole and the molten pool prescribe how well the welding succeeded. The stability is dependent on two major forces affecting the keyhole region: ablation pressure (or recoil pressure) and the forces and pressures developed by the molten pool $[9,18]$. In additional to hydrostatic pressure, the surface tension of the molten pool effect on the pressure tend to close the keyhole. The stability of the molten pool flows and the solidification front, the back of the molten pool, where material starts to solidify, also affect the formation of the weld. The high temperature differences and gradients induce flows in the molten pool. The flows affect the bead form, porosity formation, inclusion etc. The stability of the solidification front determines the kind of microstructure that forms [11].

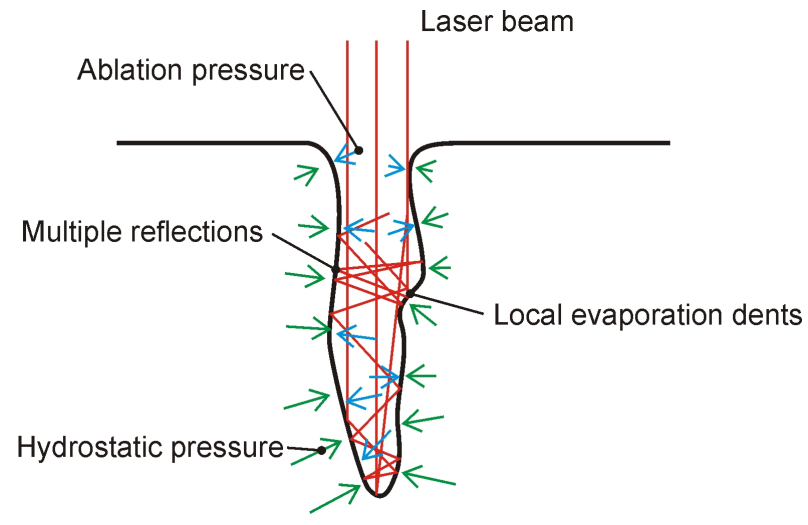

Figure 4. Schematics of keyhole physics.

\section{Parameters effect on laser welding}

Parameters, such as welding speed, power and focal point, have an effect on the stability [14,23]. Parameters affect the quality and profile of the weld bead. With low welding speeds, the heat input is larger, leading to a relatively large width of the molten pool. With high welding speeds, the molten pool width decreases. Laser power has the same effect: with more power, the welding width increases. This is due to a simple analogy: if the introduced heat is tremendous, and the heat has a sufficient amount of time to absorb into the material, the welding region increases. The heat input, $\mathrm{J} / \mathrm{mm}$, has an effect on the weld bead geometry $[2,11,22]$; with less heat input, the bead geometry is nail-shaped, whereas increasing the power width of the molten pool increases, resulting in $\mathrm{V}$-shaped bead geometry. The Marangoni effect starts to appear when the molten pool widens, resulting in a wider bead geometry through the weldable part. The schematics of the base types of bead geometry are shown in Figure 5 . The focal point is the point where the laser beam's focal point is positioned, affecting the weld depth and width. The focal point is considered as the distance from the surface of the plate.
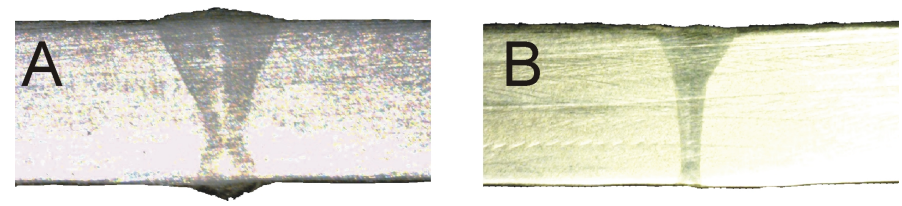

Figure 5. Different bead geometries: V-shaped and nail-shaped bead geometry. Figures from HT-laser [16] 
The weld bead soundness improves the quality of the weld. In Figure 6, the effect of heat input on fatigue strength is shown. The heat input has an inevitable effect on the behaviour of the joint; it effects geometry and fusion wellness. With a large heat input, the surface of the weld is increased. The quality of weld joint, as the dimensional accuracy of jointed parts and geometry, also has effect on fatigue strength, as discussed later $[24,25]$.

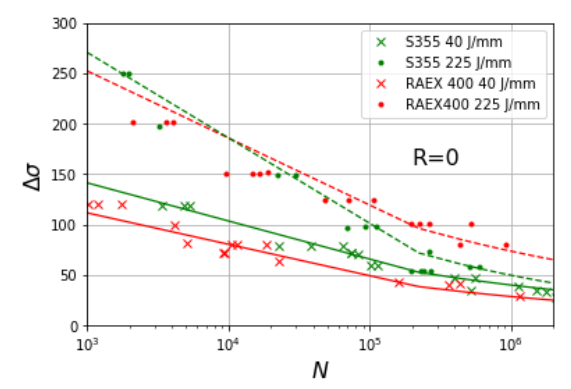

Figure 6. The effect of heat input on the fatigue durability of laser-welded lap-joint. In the figure, the number of cycles the axis is plotted in log-scale, and stress amplitude is on a normal scale, in order to emphasize the effect. Fatigue test data collected from the KeKeRa test [26]

Laser welding is generally done by an automated process, thus the welding parameters need to be preconfigured, and for the welding to succeed, the welding parameters need to be optimal. Parameters are often determined by the welder's professional skills, by the method of trial and error or by charts or equivalent $[14,15]$. The method of trial and error is a waste of resources, and it often leads to a sub-optimal solution. Parameter optimisation is usually based on a visual observation of the weld, but a visually sound weld can still include porosity, collapse, undercut, root humping etc. [14].

Laser welding is suitable for dissimilar material welding due to its original low and focused heat input [27]. The usage of dissimilar materials brings difficulties compared with similar material welding, but on the other hand, it brings great advantages in structural possibilities $[15,21,27]$.

\section{Mechanics of laser welding}

Weld joint always have a deteriorating effect on the fatigue strength of a structure [1, $3,6,7,17,28]$. Weld joint induced discontinuity is the main reason for fatigue strength deteriorating.

A weld joint always induces discontinuity in geometry and in the microstructure, which is unavoidable. The discontinuity can be divided into defects on the surface, in the microstructure and inside weld such as porosity, incomplete fusion etc. A fatigue crack always initiates from defects and imperfections [1,3,11,28]. The defects and imperfections induce stress concentrations that allow for early crack initiation in cyclic loading, leading to fatigue failure in the material. Weld induced geometrical defects are defects like porosity, cracks surface roughness and the weld geometry induced notch effect. Microstructural defects are microstructure changes, grain boundaries and impurities that act like geometrical defects, where material microstructure variation through welding zone varies material properties. Cracks leading to failure usually originate in the region between the base material and the heat affected zone, where the effect of the defects is at its highest. 
The misalignment of the joint, plate thickness, material, geometry of joint etc. also have an effect on fatigue strength [3, 24, 25, 29-32].The reduction of fatigue strength is also depended on joint -type. With thin plates, a large variation of fatigue strength is emphasised by the effect of weld geometry and the misalignment of the joint.

The load type applied affects fatigue durability as often under cyclic loading. The load type varies the driving force of a crack, and therefore, the fatigue strength of a laser welded joint varies between normal, shear and bending moment affected stress [33-36]. The fatigue strength of a $\mathrm{T}$-joint is worse than on a normal or shear loaded laser welded joint, unlike a joint welded through a conventional method, where the T-joint has better fatigue strength. The laser welded T-joint includes initially crack like defect between plates.

\section{Laser welding fatigue in general}

It is stated in the literature that the laser-welded butt-joints have a better fatigue strength compared to the convectional welded butt-joints $[3,37,38]$. The differences are due different geometry and microstructure, as seen in Figure 2. In Figure 7, the difference between the fatigue behaviour of a laser welded joint, and a MAG welded thin sheet joint is demonstrated. The data is collected from Marulo et al. (2017) [37] (Ma0...M10) and Baumgartner et al. (2015) [38] (Ba1). The stresses presented are with a fictitious notch $\rho_{f}=0.05 \mathrm{~mm}$ in both cases.

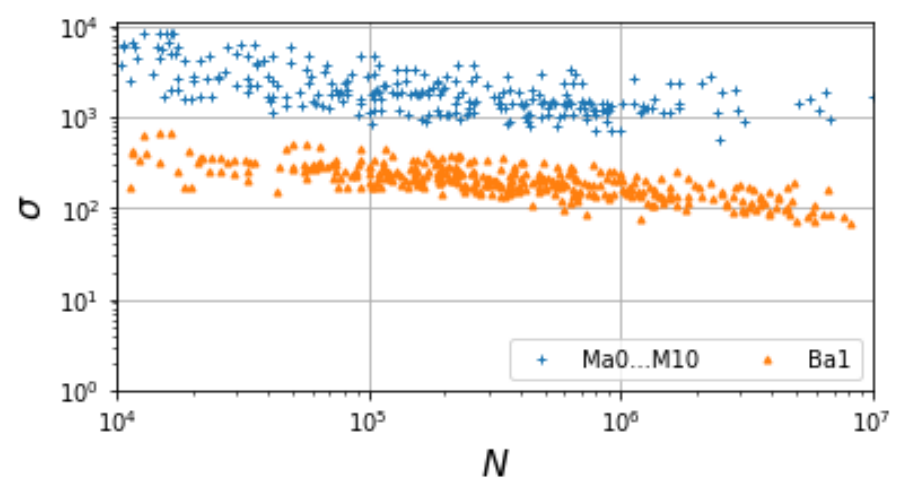

Figure 7. Notch stresses with $\rho_{f}=0.05 \mathrm{~mm}$ for laser welded joints (Ma0...M10) [37] and MAG welded thin sheets (Ba1) [38].

In the experiments, the fatigue strength of the laser welded joints has been found to have large dispersion. This has been explained with surface roughness induced sharp notches $[3,30,39,40]$. In addition to the surface roughness, there are many other factors affecting fatigue strength, which are discussed later. The surface of the weld root has significant surface roughness, where surface ripples have a notch-like effect $[30,40]$. The schematics of surface roughness are shown in Figure 8. For the evaluation of laser welded joint fatigue strength through the notch stress method, a fictitious notch with a radius $\rho=$ $0.05 \mathrm{~mm}$ is suggested. A small fictitious notch radius is justified along with the schematics of surface roughness because the probability of a notch with a radius of $\rho=0.05 \mathrm{~mm}$ is existent on the surface. Laser welding is traditionally used with thin sheets, which also increases fatigue strength scatter [41]. The geometry differs between the SAW and laser welding because the heat derives and usage of additional material (see Figure 2). The more broad heat effect and usage of the additional material make the joint geometry more 
constantly changing. Where in laser welding the heat input is highly local and additional material is not used, making the surface ripples more probable. The fictitious notch is used in the schematics of the notch stress fatigue assessment to describe defects induced stress concentration.

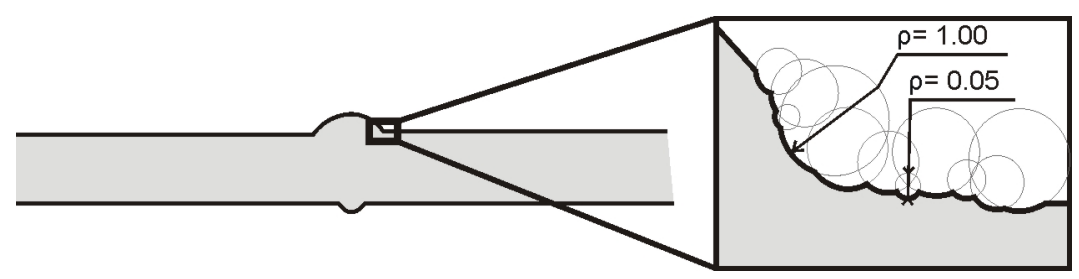

Figure 8. The schematics of surface roughness in a weld root region

Microstructure changes affect the fatigue behaviour of material [3, 42,43]. To make welding joint terminal effect, that alters material properties, is inevitable. In general, laser welding has a hardness rising effect on the heat affected zone in metals [3, 26, 44]]. In case of high-strength steels, welding can lower the quality of the microstructure in the sense of fatigue in dual-phase steels, but for low-alloy steels, it can increase it [44]. Better microstructure in laser welding is caused by low and local heat input, which leads to rapid cooling, as the surrounding material acts as a heat sink. Rapid cooling allows for the formation of martensite, which increases fatigue strength. The average grain in laser welding is smaller than through conventional methods. The microstructure formed is dependent on the welding process quality [11].

\section{Joint type}

The joint type has an effect on the fatigue behavior of the joint. The joint type determines the stress type: nominal, shear or bending. The different FAT classes of nominal stress approach in IIW correspond to different joint types while e.g. the notch stress method is assumed not to be joint type depended. [6] In the laser welding joining if done only in a small focused area leading to cavities in the welding region, which is pronounced in stake laser-welded T-joints. The fatigue assessment of laser-welded T-joint is challenging because of the complex stress state $[36,45]$. The fatigue curve slope has a steeper slope with a T-joint $[36,46]$. Because of joint geometry, the J-integral approach gives the smallest scatter index comparing to other fatigue assessments. [45]

\section{Residual stresses and strains}

Welding induces very strong thermal variation that causes thermal expansion, which yields residual stresses and strains in the structure [1,4,22,47]. Very non-homogeneous heating leads to non-homogeneous thermal expansion fields, which then lead to strain fields that yield residual stresses. These remain in the structure without an external load, as they are the result of structural self-balancing of non-homogeneous thermal expansion fields. The residual stress magnitude and distribution is the sum of the material composition, the thickness of welded parts, the welding parameters and applied restrain $[1,4]$. The material phase change affects phase induced plasticity, which also affects residual stress state [48]. Because lower heat input laser welding leads to smaller residual stresses and distortions than traditional welding processes [10]. 
The residual stress effect is seen in literature, but ignored in most fatigue assessments. The effect of residual stresses is bypassed, as it is included in $\mathrm{S}-\mathrm{N}$ curves. The residual stresses can be reduced with external treatments like preheating and hammer-, needleand shot-peening $[34,47,49]$, when after the IIW Recommendations for Fatigue Design of Welded Joints and Components, the fatigue class stress limit can be improved [50].

The presence of residual stresses affects material behaviour by affecting stress distribution and material ductility. Residual stresses generally have decreasing effect on fatigue strength [51]. Usually, residual stresses are assumed to be in the material yield strength [52], but because of variations caused by welding and cyclic loading, the yield strength differs from the yield strength of the original base material pull test. Cyclic loading decreases the residual stress level due to the combined effect of the plastic deformation and fatigue damage [7]. The residual stresses increase the maximum and mean stress levels, thus reducing the fatigue life. In view of crack growth, the tensile residual stresses increase the driving force of cracks, while compressive residual stress decreases it [53].

\section{Distortion of joint}

The welding-induced thermal strains result in distortions in the as-welded state $[3,25$, 29, 32, 41, 54]. Distortion, axial and angular misalignment decrease fatigue strength by producing stress arising from additional stress components and decreasing the nominal surface in the normal direction. The effect of misalignment is most evident in butt-joint welds and cruciform welds, where the increase in stress can be $30 \%$ to $45 \%$ [6]. The dimensional inaccuracy can also be a result of welding process. The welding process can lead to initial air-gaps, misalignment and offset.

The IIW regulations offer the stress magnification factor $k m$ to deal with misalignment. The magnification factor takes axial and angular misalignment and plate thickness into account; though some axial allowance for misalignment is already induced in the FAT classes.

\section{Plate thickness}

Thin plate welding leads to larger different initial distortions in comparison with thicker plates [41]. The initial distortion close to the weld is more curved than using thicker plates due to lower bending stiffness. The curved shape in the weld region makes angular misalignment determination difficult. Thin plate thickness $(t<5 \mathrm{~mm})$ increases scatter in fatigue strength tests.

In traditional rule-based fatigue assessments, the welded geometry is optimized, and thus, misalignment and other form-defects are obsolete $[41,55,56]$. The idealization is suitable for thicker plates, but is poorly suitable for thin plates. The response of thin plates is strongly and nonlinearly dependent on the distortions and magnitudes. In the IIW recommendations, the plate thickness can be managed by using a shallower slope in the S-N curve. The S-N curve slope of $m=5$ for normal and $m=7$ for shear stress is suggested in the literature for thin and flexible structures $[6,49,57]$.

\section{Porosity}

Inner defects of a weld have a deteriorating effect on fatigue strength. Defects such as porosity are more severe in metals like aluminium that are poorly suitable for welding. 
In the deep penetrating mode of laser welding, porosity defects are frequent [20]. It may lead to mechanical strength reductions in the joint, creep and corrosion failures [18]. Porosity reduces fatigue strength by reducing the effective bearing volume and causes stress concentrations with irregular porosity shapes [19,20]. Fatigue cracks develop from pores with the maximum size regardless of the distribution. Despite porosity affecting fatigue strength, surface defects are more critical. Base material and surface treatment have a significant effect on porosity formation [19,58]. Stainless steel and aluminium welding easily lead to porosity problems.

In fatigue design rules and regulations, the acceptable levels for porosity and other imperfections are included in S-N curves. In the IIW, porosity is combined with other imperfections and considered a single large imperfection [6]. Porosity is given as the maximum length of inclusion for fatigue classes. Different inclusion sizes are allowed for different FAT classes.

Porosity is the result of keyhole fluctuation and molten pool flows [18-20,59]. The fluctuation of the keyhole leads to bubble formation in the bottom of the keyhole, where molten pool flows are moving bubbles. Porosity is formed when the solidification front is capturing bubbles. The depth of the keyhole is strongly related to its stability. When a keyhole fluctuates violently, evaporation at the keyhole walls does not occur uniformly, but rather concentrates into bumps formed in the keyhole wall (see Figure 4) [58]. The molten pool flows affect bubble escaping, and a strong vortex in the molten pool makes escaping more difficult [60].

Laser welding is generally used for thin sheet welding. The effect of the gap between weldable parts has an effect on porosity formation, which is emphasised in thin sheets, where even a small gap may be a significant portion of the joint. [59,60]

\section{Imperfections on keyhole formation}

Keyhole defects, such as incomplete penetration, incomplete fusion and lack of fusion, are controlled with welding conditions and parameters [11,20]. A sufficient weld is more difficult to obtain with high reflectivity or high thermal conductivity materials; the reflectivity of material being emphasised. Wrong welding parameters also lead to notable welding defects such as humping, undercutting and underfilling.

The success of a weld joint affects fatigue strength. The variation of welding causes distribution in the weld fatigue test.

\section{Laser welding fatigue}

A laser welded joint geometry significantly differs from a conventional arc welded joint; this is because of the characteristic of keyhole welding, where no additional material is needed, welding is done in the penetrating mode; traditional welding is done on grooves or as filled welding. Generally, the fatigue analysis of a welded joint is done by using the nominal stress method, which is an aggregation of multiple fatigue tests with different joint types, or by using a method that considers weld geometry and the stress concentration effect - the notch stress method [3, 6, 11,37,38,50,52,61-64]. The latter is recommended, and it is based on geometry idealization, where the weld is modelled with a sharp notch on weld root. The challenge in using the notch stress method in laser welded joint assessment is that it does not form the required geometry defects. The mentioned fatigue assessment is poorly suited for laser welded joint fatigue analysis and led to unnecessary conservative results. 
The joint type/geometry effects structure behaviour, especially in overlap joints. With conventional methods, such an overlap joint type cannot be implemented. An overlap joint begins to open when affected by tensile stress, as shown in Figure 9. This leads to the distortion of the joint [65]], which effect fatigue strength. Cracks leading to a fatigue failure of the welded joint usually originate from the area between the base material and the heat-affected zone $[39,61,65]$. In this region, the effect of the microstructure and geometry defects are at the highest.

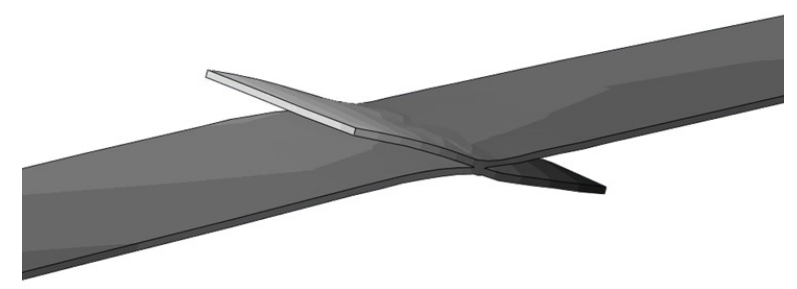

Figure 9. Magnification of distortions calculated with FEA from a lap-joint that includes residual stress. Asim et al. (2014) [65] point out the same behaviour in lap-shear specimens.

In the rules and regulations, all similar welded fatigue class joints are assumed to behave in the same way, even though their materials and methods vary [50]. The rules and regulations do not take defects and imperfections into consideration individually. Also, the same fatigue strength is assumed for all steels irrespective of their tensile strength. The stress ratio is also thought to be negligible. These assumptions are justified because the curves are based on numerous fatigue test results.

\section{Design of a laser welded joint}

The laser welded joint fatigue test results gathered from literature did show strong dispersion between fatigue strengths. A wide scatter of nominal stress range has also been reported in literature [25,30]. The chatter range index is following 1:T $=1:\left(F A T_{10 \%} /\right.$ $\left.F A T_{90 \%}\right)$. It was observed that single fatigue tests had small dispersion and results that followed a single $\mathrm{S}-\mathrm{N}$ curve were adequate, but multiple test results from various authors did not. The joint type and test circumstance, as the sufficiency of the weld, affect fatigue strength. Better fatigue strength can be achieved with a sound weld. Fatigue strength can also be increased by taking the laser weld joint type into account.

Tests results shown in table 1 are displayed in Figures 10 and 11. The fatigue test results are compared with the corresponding fatigue class. Nominal stresses are compared with the lap joint, from where stresses are inspected from the weld throat, fat class FAT 36. The notch stresses are compared with the FAT 225 class, which is independent of the joint type. Nykänen and Björk [67] analyzed mainly thick plate $(\mathrm{t}>5 \mathrm{~mm})$ butt-weld joints in the as-welded state, and concluded that the FAT 225 may lead to non-conservative results. The fictitious notch radius $\rho_{f}=0.05 \mathrm{~mm}$ is suggested in thin sheet and laser welded joint fatigue assessment [11,30,37,38, 52,63].

The reasons for this scatter are discussed in the literature and it is concluded to be related to the surface deformation, surface ripples and the effect of thin plate thickness (see Figure 8). The notch stress approach is recommended because weld fatigue originates from stress concentration. Notch stress concentration is assumed to include the effect of all defects and imperfections and, thus, covers the whole range of phenomena leading to failures. Consequently, it is proposed by multiple authors that, through the notch 
Table 1. Nominal stress fatigue test data from literature

\begin{tabular}{|c|c|c|c|c|c|c|c|c|c|}
\hline Author & Stress & Spec. & Material & $\begin{array}{c}S_{y} \\
{[\mathrm{MPa}]}\end{array}$ & $\begin{array}{c}R_{m} \\
{[\mathrm{MPa}]}\end{array}$ & $\begin{array}{c}\mathrm{t} \\
{[\mathrm{mm}]}\end{array}$ & $\mathrm{R}$ & Process & Ref. \\
\hline [12] & Nominal & Shear & Steel & 250 & 320 & 1.0 & 0.1 & $\mathrm{CO}_{2}$ & Yan \\
\hline [1] & Nominal & Shear & Steel & 210 & 320 & 1.0 & 0 & $\mathrm{CO}_{2}$ & Cho \\
\hline [66] & Nominal & Shear & Steel & 790 & 829 & 1.0 & 0.1 & - & Sh0 \\
\hline [66] & Nominal & Tensile & Steel & 790 & 829 & 3.55 & 0.1 & - & Sh1 \\
\hline [30] & Nominal & Tensile & Steel & 355 & - & 3.0 & 0 & $\mathrm{~L}-\mathrm{H}^{(1}$ & L10 \\
\hline [25] & Nominal & - & Steel & 320 & 458 & 3.0 & 0 & $\mathrm{~L}-\mathrm{H}^{(1}$ & Lm0 \\
\hline [25] & Nominal & - & Steel & 320 & 458 & - & 0.1 & $\mathrm{~L}-\mathrm{H}^{(1}$ & Lm1 \\
\hline [26] & Nominal & Shear & RAEX400 & 1000 & 1250 & 2.0 & - & Nd:YAG & $\mathrm{Ke} 0$ \\
\hline [26] & Nominal & Shear & S355 MC & 355 & 430 & 2.0 & - & Nd:YAG & Ke1 \\
\hline [54] & Nominal & Tensile & Steel & (2 & $(2$ & $3.0-4.0$ & - & - & Fr0 \\
\hline [54] & Nominal & Bending & Steel & (2 & $(2$ & $3.0-8.0$ & - & - & $\operatorname{Fr} 1$ \\
\hline$[37]^{(3}$ & $n-s^{(4}$ & Shear & St14 & 210 & 313 & $0.9-2.0$ & 0 & - & $\mathrm{Ma} 0$ \\
\hline$[37]^{(3}$ & $n-s^{(4}$ & Peel & St14 & 210 & 313 & $0.9-2.0$ & 0 & - & Ma1 \\
\hline$[37]^{(3}$ & $n-s^{(4}$ & Shear & $22 \mathrm{MnB} 5$ & - & 1500 & 1.0 & 0.1 & - & $\mathrm{Ma} 2$ \\
\hline$[37]^{(3}$ & $n-s^{(4}$ & Peel & $22 \mathrm{MnB} 5$ & - & 1500 & 1.0 & 0.1 & - & Ma3 \\
\hline$[37]^{(3}$ & $n-s^{(4)}$ & Shear & DC04 & 210 & 313 & $0.8-1.9$ & 0 & - & Ma4 \\
\hline$[37]^{(3}$ & $n-s^{(4}$ & Peel & DC04 & 210 & 313 & $0.8-1.9$ & 0 & - & Ma5 \\
\hline$[37]^{(3}$ & $n-s^{(4}$ & Tube & St35 & 235 & 313 & $1.0-2.0$ & -1 & - & Ma6 \\
\hline$[37]^{(3}$ & $n-s^{(4}$ & Shear & $2340300 \mathrm{Y}$ & 315 & 415 & 0.93 & 0 & - & Ma7 \\
\hline$[37]^{(3}$ & $n-s^{(4}$ & Tube & $\mathrm{S} 235 \mathrm{G} 2 \mathrm{~T}$ & 235 & 405 & $1.0-2.0$ & -1 & - & Ma8 \\
\hline$[37]^{(3}$ & $n-s^{(4}$ & Shear & $\mathrm{D} \times 52 \mathrm{D}+\mathrm{Z}$ & - & 343 & 1.5 & 0.1 & - & Ma9 \\
\hline$[37]^{(3}$ & $n-s^{(4}$ & Shear & XIP 1000 & - & 1500 & 1.2 & -1 & - & M10 \\
\hline
\end{tabular}

1) L-H: laser-hybrid welding

2) Multiple base plate materials

3) test series collected from literature and stress values are calculated by Marulo et al (2017) [37]

4) n-s: notch stress with $\rho_{f}=0.05$

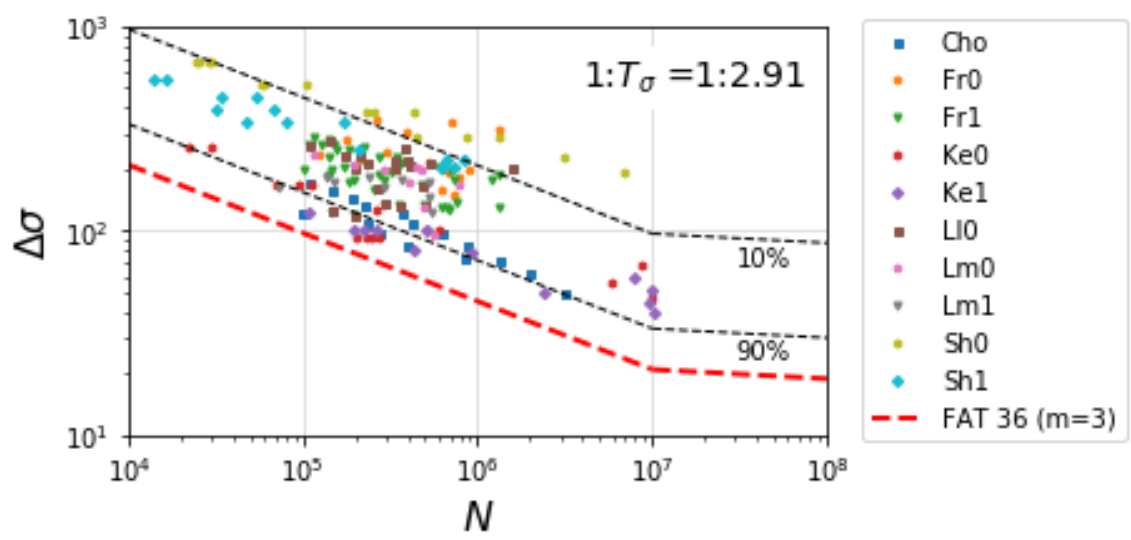

Figure 10. Laser-welded joint nominal stresses from literature compared with related fatigue FAT 36. The $T_{\sigma}$ is relatively high.

stress approach, the scatter can be reduced. In relation, a linear-elastic material model is proposed, and it may lead to inaccuracy.

In weld fatigue assessment rules and regulations, the fatigue strength of a welded joint is assumed to be independent of the base material effect, stress material and plate 


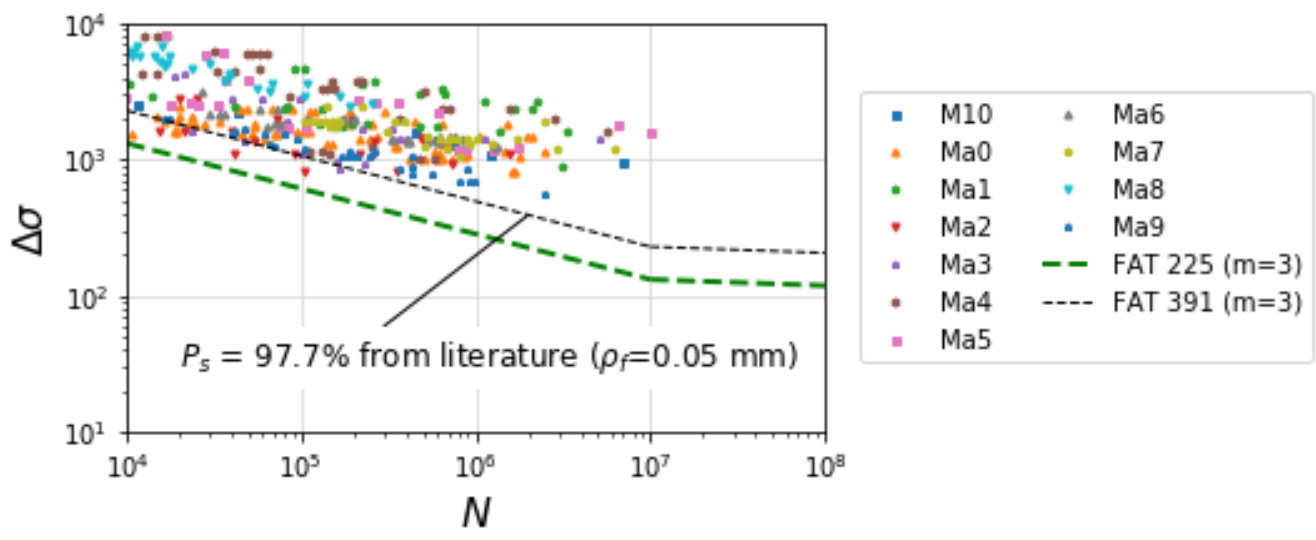

Figure 11. Laser-welded joint notch stresses from literature compared with related fatigue class FAT 225. The $97.7 \%$ probability curve with $\mathrm{m}=3$ calculated from literature test data is plotted in the Figure.

thickness (with some corrections). It can be noted that the scatter between the nominal stress approach (Fig. 10) and the notch stress approach (Fig. 11) stress ranges are not significantly concentrated; therefore, it can be concluded that the scatter of fatigue cant be explained entirely with the effect of a surface notch.

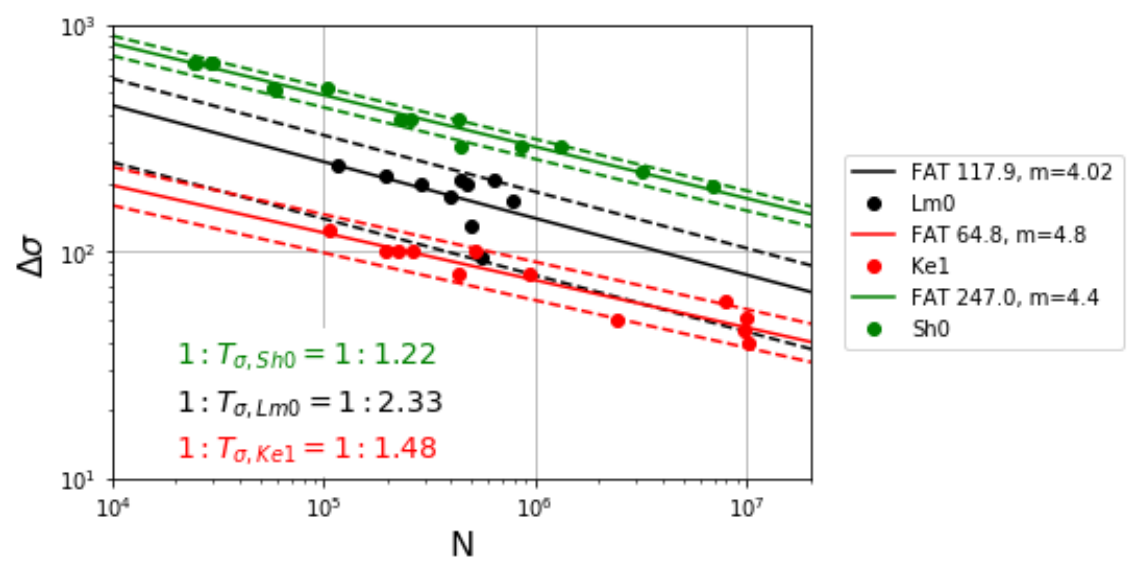

Figure 12. Fatigue stress variation of fatigue test from different authors. In the figure the dispersion is shown as a FAT -class.

In Figure 12, the fatigue stress variation from different authors is shown. The test results are with butt-joint ( $\mathrm{Lm} 0)$ and lap-joints (Ke1 and Sh0). The corresponding materials are S355 with $\mathrm{Lm} 0$ and Ke1, and SPFH780 with Sh0. The figure shows the variation in fatigue strength and the slope of the curve between different fatigue tests. This indicates that the material and joint type have effect fatigue behaviour. These factors, among other factors such as defects, can be considered in fatigue behaviour study.

\section{Advanced fatigue assessments}

There are several advanced welding fatigue assessment methods presented in literature. In the assessments the load ratio, joint geometry, plate thickness, etc. are taken into account. The novel fatigue assessments are general fatigue assessments utilized in weld joint, such as continuum damage mechanism approach in welding, and development of traditional fatigue assessments to predict fatigue more accuracy, such as various strain- 
based approaches. The fatigue assessments can be also improved by adding geometric variables such as distortions to model. The plate thickness has a major role in fatigue behaviour of welded joint, especially with thin sheets with thickness under $5 \mathrm{~mm}$. Eggert et al [29], Fricke et al [54], and Lillemäe at al [31,32,41] have shown that by taking initial distortion of thin plate in account with the hot spot assessments, the results can be improved.

\section{Notch based approaches}

The most developments have been presented for the IIW's notch stress concept. The initial idea of notch stress is to model weld with fictitious rounding with radius $r_{r e f}=1$ mm and compare stresses on FAT-225 -class. The toe of the weld acts like notch, causing stress concentrations, which can be assumed to explain the most fatigue behaviour. The $r_{r e f}=1 \mathrm{~mm}$ suits poorly with thin plates and with the geometry of laser welded joints and therefore fictitious rounding $0.05 \mathrm{~mm}$ is suggested for thin plates and laser welded joints [50]. Later the small reference radius have been validated by e.g Bruder et al. [63], Baumgartner et al. [38], Liinalampi et al. [30], Liu et al. [11], Marulo et al. [37]. For laser welded joints also V-shaped notch have been suggested [3]. The stresses on the notch surface are higher and increase of structural stress can be describe with notch factor $K_{w}$. The small fictitious rounding demands stress averaging over thickness or inspecting stress from distance from surface. The stress can be averaged over thickness with length corresponding to Neuber's hypothesis of microstuctural support or by using Taylor's critical distance approach $[37,38,61,68]$. The surface roughness varies in welded joints and commonly stress averaging length $\rho^{*}=0.4 \mathrm{~mm}$ is suggested for welds. Liinalmpi et al. [30] studied actual notch geometry based on 3D laser microscopy and resulting $K_{w}$. They stated that the for welds the ferritic steels $\rho^{*}(0.05-0.1 \mathrm{~mm})$ can be used for thin plates using measured geometry. Marulo et al. [37] re-analysed large number of thin laserwelded joints to compare stress averaging methods and stated that the Taylor's critical distance approach gives a better scatter band than the Neuber's stress averaging.

In the notch strain approach, material properties dominate the fatigue life [52,57,61]. The fatigue endurance is investigated with material elasto-plastic stress-strain response failure criteria. The framework of notch strain method is that the mechanical behavior of is comparable in experimental specimens. The notch strain concept is further developed in e.g strain-based approach and 3R-approach.

\section{Continuum damage mechanism approach}

The continuum damage mechanism approach, CDM, is an approach based on the mechanical behaviour of material and macroscopic progressive damage [7,69,70]. The approach deals with mechanical behaviour of material in a macroscopic scale and plastic deformations that occurs due cyclic loading. The fatigue behaviour is controlled with a damage model. The CDM applied to welded joints by Do et al [69] and Shen et al [7]. In the framework of the approach, the residual stresses and distortions, material defects and geometric defects, can be taken into account.

\section{Strain-based approach}

In strain-based approach introduced Remes et al. [3, 24, 35, 71] consider the actual weld notch geometry and the variation in the microstucture characteristics of the material. In 
the framework of approach the fatigue crack growth simulation form the crack initiation to the critical crack length is possible. The material plasticity and microstructures grain sizes are taken into account in notch region, where the crack growth is calculated. The approach allows calculating the progress and direction of crack growth.

\section{$3 R$}

The novel notch stress approach, 3R, is intoduced by Nykänen and Björk [49,72]. The approach takes material behaviour and stress ratio into account in cyclic loading. The $3 \mathrm{R}$ method is based on a local stress ratio, $R_{\text {local }}$, and with it, the residual stress effect, a applied stress ratio, and the material property can taken into account. The $R_{\text {local }}$ is obtained with the notch strain approach and fatigue behaviour is utilized with a damagemodel such as Smith-Watson-Topper.

\section{Linear elastic fracture mechanism}

Multiple approaches are base on linear elastic fracture mechanism, LEFM, such as the stress intensity factor method, SIF, the peak stress method, LEFM, and the strain-energydensity method, SED, and the J-integral method [73,74]. With novel approaches such as presented in [35] the fatigue crack growth can be calculated with taking account the microstructure. The LEFM approaches work better than nominal or notch based approaches for some joint types. In case of stake-welded T-joint the J-integral approach gives most accurate predictions $[36,45,46]$.

\section{Applying the statistical probability in laser welded joint fatigue assessment}

The defects have a deteriorating effect on fatigue life, and the size and occurrence of defects are statistical; thus, the dispersion of fatigue strength can be explained [75, 76]. Murakami $[75,77]$ suggested and proved via tests that the defect size has an effect on fatigue ductility; bigger defects have a bigger impact. In Murakami's theory, theory, a critical area $\sqrt{\text { area }}$, is used instead of crack length. $\sqrt{\text { area }}$ describes the effect of small surface defects, small surface cracks and nonmetallic surface inclusions.

The statistical analysis, in base of welded joint, can be done on the basis of Murakami's theory that defect affects fatigue curve transformation. The actual defect size is not known and therefore a relative defect size is used. The notch stress analysis is based on fictitious notch, which have defect like effect. A fictitious notch with radius $0.05 \mathrm{~mm}$ is suggested for laser welded joints based on research and test results, consequently the $\rho_{f}=0.05 \mathrm{~mm}$ is used as relative defect size in calculations.

The statistical study was made for the fatigue test data was collected from L10 [30], Lm0 [31], Lm1 [31], Ke1 [26]. The ratio of the literature test data for S355, $\sigma_{i}^{*}$, and stress of $F A T_{r e f}, \sigma_{i}$, in corresponding $N$ was calculated for each test data points. The $F A T_{r e f}$ was assumed to correspond with $\sqrt{a r e a}_{\text {ref }}$ as the actual defect distribution is not known. The ratios of $\sigma_{i}^{*}$ and $\sigma_{i}$, presented ad relative defect size, $\sqrt{\text { area }} / \sqrt{\text { area }}$ ref , were fit in log-normal distribution. The schematics of analysis is shown in Figure 13.

Assuming that a defect size of $\rho_{f}=0.05 \mathrm{~mm}$ is present with a $50 \%$ probability, the cumulative density of calculated relative defect size can be presented with a function of the defect size $\sqrt{a r e a}$. The expected defect size is shown in Figure 14 .

The welded joint fatigue behavior is sum of multiple factors such as soundness of weld joint, porosity, surface roughness, residual stresses, distortions etc. Studying the 

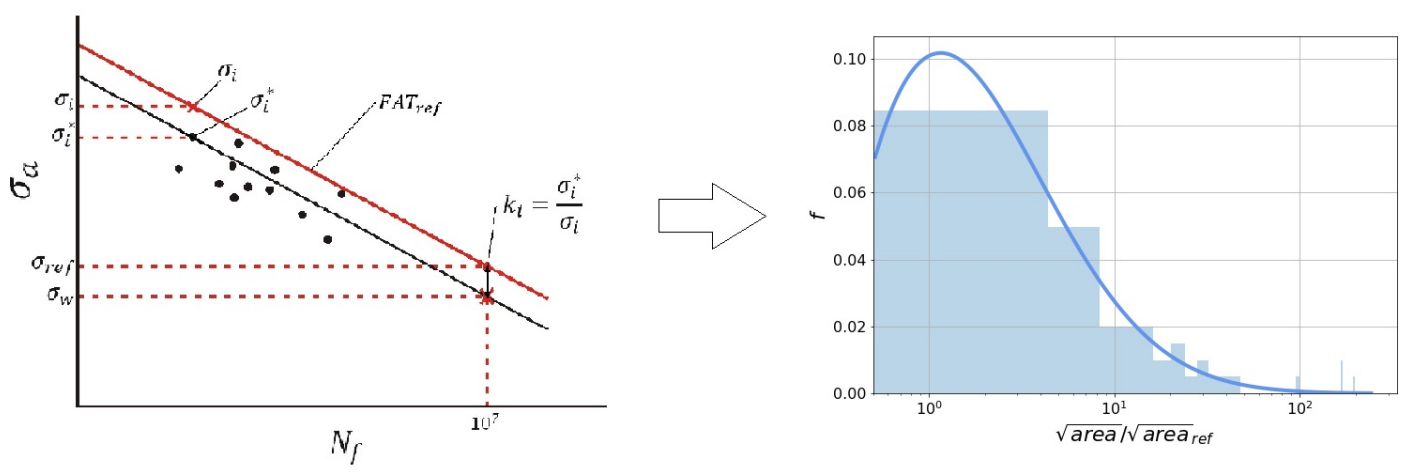

Figure 13. The schematics of statistical calculations. The laser welding fatigue test results are compared to reference FAT curve.

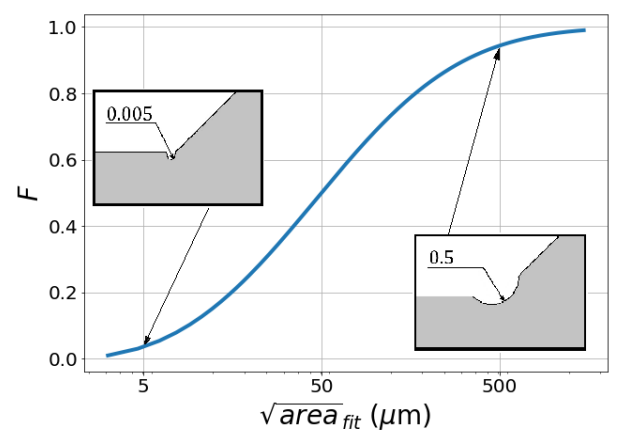

Figure 14. The calculated log-normal distribution presented as cumulative density of assumed probable defect size.

dispersion of the fatigue test data in view of Murakami's theory that the defects affect fatigue curve transformation, the assumed defect distribution can be calculated. The assumed global defect size calculated from nominal fatigue data includes all defects causing dispersion on fatigue data. The statistical analysis can expand to processing different defects separately if ones are known. For an example if the statistical dispersion of distortion, residual stresses or porosity is known, it can be excluded from global defect size. The approach allows to map a different defects effect on fatigue strength. The statistical analysis of defects improve fatigue prediction of the welded joints.

\section{Conclusion}

Convectional fatigue strength assessment suitability for a laser-welded joint is discussed, and it is noted that using conventional weld fatigue assessment leads to conservative results. The Traditional geometry idealization of convectional methods does not fit well to laser-welded joints because of the different bead shapes. With advanced fatigue assessment presented with literature, more precise evaluations can be made. But when more phenomena such as material behavior in cyclic loading, distortions, microstructure, etc. the factors in fatigue assessment increase. The fatigue assessment precision could be improved by introducing a statistical approach.

In this study, the process of laser welding was discussed. The formation of a laser weld is processed from the scope of the fatigue strength of a laser welded joint. In the welding process, the formation of defects that have an effect on fatigue strength is likely. Defects such as porosity, lack of fusion or misalignment affect fatigue strength and 
explain fatigue strength dispersion. When the process is understood, defect distribution can be included in the statistical probability in fatigue assessment. The article presented a method to divine dispersion of fatigue stresses in the probability density of fatigue stress-reducing defects. The probability of defects and sizes of defects can be utilized to improve fatigue assessment statistical accuracy. The statistical analysis was made on the basis of Murakami's theory.

\section{References}

[1] S.K. Cho, Y.S. Yang, K.J. Son, and J.Y. Kim. Fatigue strength in laser welding of the lap joint. Finite Elements in analysis and design, 40(9):1059-1070, 2004.

[2] F. Caiazzo, V. Alfieri, F. Cardaropoli, and V. Sergi. Investigation on edge joints of inconel 625 sheets processed with laser welding. Optics \& Laser Technology, 93(Supplement C):180 - 186, 2017. URL: http://www.sciencedirect.com/ science/article/pii/S0030399216310477, doi:https://doi.org/10.1016/j. optlastec.2017.03.011.

[3] H. Remes. Strain-based approach to fatigue strength assessment of laser-welded joints,. PhD thesis, Helsinki University of Tecnology, 2008.

[4] M. Zain-ul Abdein, D. Nelias, J.F. Jullien, and D. Deloison. Prediction of laser beam welding-induced distortions and residual stresses by numerical simulation for aeronautic application. Journal of Materials Processing Technology, 209(6):2907 - 2917, 2009. URL: http://www.sciencedirect.com/ science/article/pii/S0924013608005542, doi:https://doi.org/10.1016/j. jmatprotec.2008.06.051.

[5] K. Jarmai. Optimum design of welded structures. Rakenteiden Mekaniikka, 50(3):326-329, 2017. URL: https://rakenteidenmekaniikka.journal.fi/ article/view/65153, doi:https://doi.org/10.23998/rm.65153.

[6] A. Hobbacher. Recommendations for fatigue design of welded joints and components. New York: Welding Recearch Council, 2009.

[7] F. Shen, B. Zhao, L. Li, C.K. Chua, and K. Zhou. Fatigue damage evolution and lifetime prediction of welded joints with the consideration of residual stresses and porosity. International Journal of Fatigue, 103(Supplement C):272-279, 2017. URL: http://www.sciencedirect.com/science/article/pii/ S0142112317302645, doi:https://doi.org/10.1016/j.ijfatigue.2017.06.014.

[8] T. Frondelius, H. Tienhaara, and M. Haataja. History of structural analysis \& dynamics of Wärtsilä medium speed engines. Rakenteiden Mekaniikka, 51(2):1-31, 2018. URL: https://doi.org/10.23998/rm.69735.

[9] J.C. Ion. Laser Processing of Engineering Materials. Oxford: Elsevier ButterworthHeinemann, 2005. p. 556 ISBN 0-7506-6079-1.

[10] G.A. Moraitis and G.N. Labeas. Residual stress and distortion calculation of laser beam welding for aluminum lap joints. Journal of materials processing technology, 198(1):260-269, 2008. 
[11] S. Liu, G. Mi, F. Yan, C. Wang, and P. Jiang. Correlation of high power laser welding parameters with real weld geometry and microstructure. Optics $\&$ Laser Technology, 94:59-67, 2017.

[12] Y.S. Yang and S.H. Lee. A study on the joining strength of laser spot welding for automotive applications. Journal of Materials Processing Technology, 94(2):151-156, 1999.

[13] Z. Gao, X. Shao, P. Jiang, L. Cao, Q. Zhou, C. Yue, Y. Liu, and C. Wang. Parameters optimization of hybrid fiber laser-arc butt welding on 3161 stainless steel using kriging model and ga. Optics \& Laser Technology, 83(Supplement C):153- 162, 2016. URL: http://www.sciencedirect.com/ science/article/pii/S0030399215302541, doi:"https://doi.org/10.1016/j. optlastec.2016.04.001.

[14] P. Jiang, C. Wang, Q. Zhou, X. Shao, L. Shu, and X. Li. Optimization of laser welding process parameters of stainless steel 3161 using fem, kriging and nsga-ii. Advances in Engineering Software, 99(Supplement C):147-160, 2016.

[15] Y. Ai, X. Shao, P. Jiang, P. Li, Y. Liu, and W. Liu. Welded joints integrity analysis and optimization for fiber laser welding of dissimilar materials. Optics and Lasers in Engineering, 86:62-74, 2016.

[16] HT Laser Oy. URL: http://htlaser.fi/en/.

[17] V. Kujanpää, A. Salminen, and J. Vihinen. Lasertyöstö. Helsinki: Teknologiateollisuus ry., 2005.

[18] O.T. Ola and F.E. Doern. Keyhole-induced porosity in laser-arc hybrid welded aluminum. The International Journal of Advanced Manufacturing Technology, 80(80):3 -10, Sep 2015. URL: https : //doi .org/10.1007/s00170-015-6987-4, doi : https: //doi.org/10.1007/s00170-015-6987-4.

[19] R. Lin, H. Wang, F. Lu, J. Solomon, and B.E. Carlson. Numerical study of keyhole dynamics and keyhole-induced porosity formation in remote laser welding of al alloys. International Journal of Heat and Mass Transfer, 108:244-256, 2017.

[20] S. Katayama. Handbook of Laser Welding Technologies. Woodhead Publishing Series in Electronic and Optical Materials. Elsevier Science, 2013. URL: https://books . google.com/books?id=wWZEAgAAQBAJ.

[21] Z. Sun and J.C. Ion. Laser welding of dissimilar metal compinations. Journal Of Materials Science, 30(30):4205-4214, 1995. doi:https://doi.org/10.1007/ BF00361499.

[22] S.A. Tsirkas, P. Papanikos, and T. Kermanidis. Numerical simulation of the laser welding process in butt-joint specimens. Journal of materials processing technology, 134(1):59-69, 2003.

[23] J.A. Alcock and B. Baufeld. Diode laser welding of stainless steel 304l. Journal of Materials Processing Technology, 240:138-144, 2017. doi:https://doi.org/10. 1016/j . jmatprotec .2016.09.019. 
[24] H. Remes, J. Romanoff, I. Lillemäe, D. Frank, S. Liinalampi, P. Lehto, and P. Varsta. Factors affecting the fatigue strength of thin-plates in large structures. International Journal of Fatigue, 101:397-407, 2017.

[25] I. Lillemäe, S. Liinalampi, A. Remes, . A. Niemelä. Fatigue strength of thin laserhybrid welded full-scale deck structure. International Journal of Fatigue, 95:282-292, 2017.

[26] KeKeRa koesarja 4 - 355 MC leikkausvoimakokeet ja väsytyskokeet raportti. Oulun yliopiston Kerttu Saalasti Instituutti, 2017.

[27] C. Yuce, M. Tutar, F. Karpat, and N. Yavuz. The optimization of process parameters and microstructural characterization of fiber laser welded dissimilar hsla and mart steel joints. Metals, 6(10), 2016. URL: http://www.mdpi.com/2075-4701/6/10/ 245, doi:https://doi.org/10.3390/met6100245.

[28] D. Radaj and M. Vormwald. Advanced Methods of Fatigue Assessment. Berlin: Springer, 2013.

[29] L. Eggert, W. Fricke, and H. Paetzold. Fatigue strength of thin-plated block joints with typical shipbuilding imperfections. Welding in the World, 56(11-12):119-128, 2012.

[30] S. Liinalampi, H. Remes, P. Lehto, I. Lillemäe, J. Romanoff, and D. Porter. Fatigue strength analysis of laser-hybrid welds in thin plate considering weld geometry in microscale. International Journal of Fatigue, 87(Supplement C):143-152, 2016. URL: http://www.sciencedirect.com/science/article/pii/ S0142112316000293, doi:https://doi.org/10.1016/j.ijfatigue.2016.01.019.

[31] I. Lillemäe, S. Liinalampi, H. Remes, E. Avi, and J. Romanoff. Influence of welding distortion on the structural stress in thin deck panels. In Proceedings of the 13th International Symposium on Practical design of ships and other floating structures, Copenhagen, Denmark, 2016.

[32] I. LillemäeAvi, H. Remes, Y. Dong, Y. Garbatov, Y. Quéméner, L. Eggert, Q. Sheng, and J. Yue. Benchmark study on considering welding-induced distortion in structural stress analysis of thin-plate structures. Progress in the Analysis and Design of Marine Structures. London: Taylor \& Francis Group, pages 387-394, 2017. doi:https: //doi.org/10.1201/9781315157368-45.

[33] P. Lazzarin and P. Livieri. Notch stress intensity factors and fatigue strength of aluminium and steel welded joints. International Journal of Fatigue, 23(3):225 - 232, 2001. URL: http://www.sciencedirect.com/science/article/pii/ S0142112300000864, doi:https://doi .org/10.1016/S0142-1123(00)00086-4.

[34] C.M. Sonsino. Effect of residual stresses on the fatigue behaviour of welded joints depending on loading conditions and weld geometry. International Journal of Fatigue, 31(1):88-101, 2009.

[35] H. Remes. Strain-based approach to fatigue crack initiation and propagation in welded steel joints with arbitrary notch shape. International Journal of Fatigue, $52: 114-123,2013$. 
[36] P. Gallo, H. Remes, and J. Romanoff. Influence of crack tip plasticity on the slope of fatigue curves for laser stake-welded t-joints loaded under tension and bending. International Journal of Fatigue, 99:125 - 136, 2017. doi:https://doi.org/10. 1016/j.ijfatigue.2017.02.025.

[37] G. Marulo, J. Baumgartner, and F. Frendo. Fatigue strength assessment of laser welded thin-walled joints made of mild and high strength steel. International Journal of Fatigue, 96:142-151, 2017.

[38] J. Baumgartner, H. Schmidt, E. Ince, T. Melz, and K. Dilger. Fatigue assessment of welded joints using stress averaging and critical distance approaches. Welding in the World, 59(5):731-742, 2015.

[39] M. Alam, Z. Barsoum, P. Jonsén, H.Å. Häggblad, and A. Kaplan. Fatigue behaviour study of laser hybrid welded eccentric fillet joints: Part i. In Nordic Conference on Laser Processing of Materials: 24/08/2009-26/08/2009, 2009. ATV-SEMAPP.

[40] B. Schork, P. Kucharczyk, M. Madia, U. Zerbst, J. Hensel, J. Bernhard, D. Tchuindjang, M. Kaffenberger, and M. Oechsner. The effect of the local and global weld geometry as well as material defects on crack initiation and fatigue strength. Engineering Fracture Mechanics, 2017.

[41] I. Lillemäe, H. Remes, and J. Romanoff. Influence of initial distortion on the structural stress in 3mm thick stiffened panels. Thin-Walled Structures, 72:121-127, 2013.

[42] A. Leppänen, A. Kumpula, J. Vaara, M. Cattarinussi, J. Könnö, and T. Frondelius. Thermomechanical fatigue analysis of cylinder head. Rakenteiden Mekaniikka, 50(3):182-185, 2017.

[43] A. Kumpula, J. Vaara, A. Leppänen, and T. Frondelius. Nodular cast iron onera fatigue model fitting. Rakenteiden Mekaniikka, 50(3):179-181, 2017.

[44] J.W. Sowards, E.A. Pfeif, M.J. Connolly, J.D. McColskey, S.L. Miller, B.J. Simonds, and J.R. Fekete. Low-cycle fatigue behavior of fiber-laser welded, corrosion-resistant, high-strength low alloy sheet steel. Materials \& Design, 121:393-405, 2017.

[45] D. Frank, H. Remes, and J. Romanoff. J-integral-based approach to fatigue assessment of laser stake-welded t-joints. International Journal of Fatigue, 47:340-350, 2013.

[46] D. Frank, H. Remes, and J. Romanoff. Fatigue assessment of laser stake-welded t-joints. International Journal of Fatigue, 33(2):102-114, 2011.

[47] A. P. Macwood and R. C. Crafer. Thermal modelling of laser welding and related processes: a literature review. Optics \& Laser Technology, 37(2):99 - 115, 2005.

[48] J.B. Leblond, J. Devaux, and J.C. Devaux. Mathematical modelling of transformation plasticity in steels $\mathrm{i}$ : case of ideal-plastic phases. International journal of plasticity, 5(6):551-572, 1989. 
[49] T. Nykänen, H. Mettänen, T. Björk, and A. Ahola. Fatigue assessment of welded joints under variable amplitude loading using a novel notch stress approach. International Journal of Fatigue, 101(Part 2):177-191, 2017. URL: http://www. sciencedirect.com/science/article/pii/S0142112316304315, doi:https:// doi.org/10.1016/j.ijfatigue.2016.12.031.

[50] A Hobbacher. Recommendations for fatigue design of welded joints and components. iiw document xiii-2151-07. XV-1254r1-07, Paris2007, 2007.

[51] R. Kokko. Modern fatigue analysis methodology for laser welded joints. Master's thesis, University of Oulu, 2018.

[52] D. Radaj, C.M. Sonsino, and W. Fricke. Fatigue assessment of welded joints by local approaches. Woodhead publishing, 2006.

[53] N.T. Ninh and M.A. Wahab. The effect of residual stresses and weld geometry on the improvement of fatigue life. Journal of materials processing technology, 48(1-4):581 $-588,1995$.

[54] W. Fricke, H. Remes, O. Feltz, I. Lillemäe, D. Tchuindjang, T. Reinert, A. Nevierov, W. Sichermann, M. Brinkmann, and T. Kontkanen. Fatigue strength of laser-welded thin-plate ship structures based on nominal and structural hot-spot stress approach. Ships and Offshore Structures, 10(1):39-44, 2015. URL: https : //doi .org/10 .1080/ 17445302.2013 .850208 .

[55] A. Ahola, H. Mettänen, and T. Björk. Kuormitustavan ja symmetrisyyden vaikutus kuormaa kantamattomien hitsausliitosten väsymiseen — tehollisen lovijännityksen ja murtumismekaniikan menetelmien vertailu. Rakenteiden Mekaniikka, 50(3):153-157, 2017. URL: https://rakenteidenmekaniikka.journal.fi/article/view/65049, doi:https://doi.org/10.23998/rm.65049.

[56] I. Valkonen and A. Valkonen. Tuotantokäyttöön soveltuva edullinen menetelmä hitsin juuren puolen väsymiseliniän arvioimiseksi. Rakenteiden Mekaniikka, 50(3):220-223, 2017. URL: https://rakenteidenmekaniikka.journal.fi/article/view/64570, doi:https://doi.org/10.23998/rm.64570.

[57] M. Malikoutsakis and G Savadis. Fatigue assessment of thin-welded joints with pronounced terminations. Fatigue $\& 6$ Fracture of Engineering Materials $\& 5$ Structures, $37(7): 782-799,2014$.

[58] X. Zhang, W. Chen, G. Bao, and L. Zhao. Suppression of porosity in beam weaving laser welding. Science and technology of welding and joining, 9(4):374-376, 2004.

[59] W. Meng, Z. Li, J. Huang, Y. Wu, and R. Cao. Effect of gap on plasma and molten pool dynamics during laser lap welding for t-joints. The International Journal of Advanced Manufacturing Technology, 69(5-8):1105-1112, 2013.

[60] W. Meng, Z. Li, F. Lu, Y. Wu, J. Chen, and S. Katayama. Porosity formation mechanism and its prevention in laser lap welding for t-joints. Journal of Materials Processing Technology, 214(8):1658-1664, 2014.

[61] D. Radaj. Design and analysis of fatigue resistant welded structures. Elsevier, 1990. 
[62] D. Radaj, C.M. Sonsino, and W. Fricke. Recent developments in local concepts of fatigue assessment of welded joints. International Journal of Fatigue, 31:2-11, 2009.

[63] T. Bruder, K. Störzel, J. Baumgartner, and H. Hanselka. Evaluation of nominal and local stress based approaches for the fatigue assessment of seam welds. International Journal of Fatigue, 34(1):86-102, 2012.

[64] M.M. Pedersen, O.Ø. Mouritsen, M.R. Hansen, J.G. Andersen, and J. Wenderby. Re-analysis of fatigue data for welded joints using the notch stress approach. International Journal of Fatigue, 32(10):1620-1626, 2010.

[65] K. Asim, K. Sripichai, and J. Pan. Fatigue behavior of laser welds in lap-shear specimens of high strength low alloy steel sheets. International Journal of Fatigue, 61:283 - 296, 2014.

[66] S. Sharifimehr, A. Fatemi, S. C. Cha, M.K. Bae, and S.H. Hong. Fatigue behavior of ahss lap shear and butt arc welds including the effect of periodic overloads and underloads. International Journal of Fatigue, 87:6-14, 2016.

[67] T. Nykänen and T. Björk. Assessment of fatigue strength of steel butt-welded joints in as-welded condition - alternative approaches for curve fitting and mean stress effect analysis. Marine Structures, 44:288-310, 2015. doi:https://doi.org/10.1016/j. marstruc.2015.09.005.

[68] H. Neuber. Über die berücksichtingung der spannungkonzentration bei festigkeitsberechnungen (consideration of stress concentration in strength calculations). Konstruction, 20:245-251, 1968.

[69] V.N. Van Do, C.H. Lee, and K.H. Chang. High cycle fatigue analysis in presence of residual stresses by using a continuum damage mechanics model. International Journal of Fatigue, 70:51-62, 2015. URL: http://www.sciencedirect.com/ science/article/pii/S0142112314002187, doi:https://doi.org/10.1016/j. ijfatigue.2014.08.013.

[70] J. Jussila, S. Holopainen, T. Kaarakka, R. Kouhia, J. Mäkinen, H. Orelma, N.S. Ottosen, M. Ristimaa, and T. Saksala. A new paradigm for fatigue analysis-evolution equation based continuum approach. Rakenteiden Mekaniikka, 50(3):333-336, 2017.

[71] H. Remes, P. Varsta, and J. Romanoff. Continuum approach to fatigue crack initiation and propagation in welded steel joints. International Journal of Fatigue, 40:16-26, 2012.

[72] T. Nykänen and T. Björk. A new proposal for assessment of the fatigue strength of steel butt-welded joints improved by peening (hfmi) under constant amplitude tensile loading. Fatigue $\&$ Fracture of Engineering Materials \& Structures, 39(5):566582, 2016. FFEMS-6049.R2. URL: http://dx.doi.org/10.1111/ffe.12377, doi: https://doi.org/10.1111/ffe.12377.

[73] G. Meneghetti. The peak stress method applied to fatigue assessments of steel and aluminium fillet-welded joints subjected to mode i loading. Fatigue \& Fracture of Engineering Materials \& Structures, 31(5):346-369, 2008. 
[74] D. Radaj. State-of-the-art review on the local strain energy density concept and its relation to the j-integral and peak stress method. Fatigue \& Fracture of Engineering Materials \& Structures, 38(1):2-28, 2015.

[75] Y. Murakami. Metal fatigue: effects of small defects and nonmetallic inclusions. Elsevier, 2002.

[76] J. Vaara, A. Mäntylä, and T. Frondelius. Brief review on high-cycle fatigue with focus on non-metallic inclusions and forming. Rakenteiden Mekaniikka, 50(3):146$152,2017$.

[77] Y. Murakami and K.J. Miller. What is fatigue damage? a view point from the observation of low cycle fatigue process. International Journal of Fatigue, 27(8):9911005, 2005.

Rami Kokko

Lumijoentie 8

90400 Oulu

rami.kokko@gbw.fi

Joona Vaara, Teemu Kuivaniemi, Tero Frondelius

Wärtsilä

Järvikatu 2-4

65100 Vaasa

joona.vaara@wartsila.com, teemu.kuivaniemi@wartsila.com, tero.frondelius@wartsila.com

Tero Frondelius

University of Oulu

Pentti Kaiteran katu 1

90014 Oulu

tero.frondelius@oulu.fi 